\title{
The early evolution of postcranial skeletal pneumaticity in sauropodomorph dinosaurs
}

\author{
Adam M. Yates, Mathew J. Wedel, and Matthew F. Bonnan \\ Acta Palaeontologica Polonica 57 (1), 2012: 85-100 doi: http://dx.doi.org/10.4202/app.2010.0075
}

Postcranial skeletal pneumaticity (PSP) is present in a range of basal sauropodomorphs spanning the basal sauropodomorph-sauropod transition. We describe the PSP of five taxa, Plateosaurus engelhardti, Eucnemesaurus fortis, Aardonyx celestae, Antetonitrus ingenipes, and an unnamed basal sauropod from Spion Kop, South Africa (hereafter referred to as the Spion Kop sauropod). The PSP of Plateosaurus is apparently sporadic in its occurrence and has only been observed in very few specimens, in which it is of very limited extent, affecting only the posterior cervical vertebrae and possibly the mid dorsals in one specimen. The PSP of Eucnemesaurus, Aardonyx, Antetonitrus, and the Spion Kop sauropod consists of subfossae (fossa-within-fossa structures) that excavate the vertices of the posterior infradiapophyseal fossae of the posterior dorsal vertebrae. These subfossae range from simple shallow depressions (Eucnemesaurus) to deep, steepsided, internally subdivided and asymmetrically developed chambers (Antetonitrus). The middle and anterior dorsal vertebrae of these taxa lack PSP, demonstrating that abdominal air sacs were the source of the invasive diverticula. The presence of pneumatic features within the infradiapophyseal fossae suggest that the homologous fossae of more basal saurischians and dinosauriforms were receptacles that housed pneumatic diverticula. We suggest that it is probable that rigid non-compliant lungs ventilated by compliant posterior air sacs evolved prior to the origination of Dinosauria.

Key words: Sauropodomorpha, Sauropoda, postcranial skeletal pneumaticity, air-sacs, Triassic, Jurassic, South Africa.

Adam M. Yates [yatesam@gmail.com], Bernard Price Institute, University of the Witwatersrand, Johannesburg 2050, South Afric; apresent address: Museum of Central Australia, Araluen Cultural Precinct, P.O. Box 3521, Alice Springs, Northern Territory 0871, Australia; Mathew J. Wedel [mathew.wedel@gmail.com ], College of Osteopathic Medicine of the Pacific and College of Podiatric Medicine, Western University of Health Sciences, Pomona, CA 91766; Matthew F. Bonnan [MF-Bonnan@wiu.edu], Department of Biological Sciences, Western Illinois University, Macomb, IL 6145. 
This is an open-access article distributed under the terms of the Creative Commons

Attribution License (for details please see creativecommons.org), which permits unrestricted use, distribution, and reproduction in any medium, provided the original author and source are credited.

FarF Full text $(1,265.9 \mathrm{kB})$ 